\section{Effect of Glaze Cooling Rate on Mechanical Properties of Conventional and Pressed Porcelain on Zirconia}

Diogo Longhini' ${ }^{1}$ Cibele Oliveira de Melo Rocha', Igor Studart Medeiros², Renata Garcia Fonseca ${ }^{1}$, Gelson Luis Adabo ${ }^{1}$

\author{
'Department of Dental Materials \\ and Prosthodontics, Araraquara \\ Dental School, UNESP - \\ Universidade Estadual Paulista, \\ Araraquara, SP, Brazil \\ ${ }^{2}$ Department of Biomaterials \\ and Oral Biology, Dental School \\ of USP - Universidade de São \\ Paulo, São Paulo, SP, Brazil
}

Correspondence: Gelson Luis Adabo, Rua Humaitá, 1680, 14801-903 Araraquara, SP, Brasil. Tel: +55-16-3301-6415. e-mail: adabo@foar.unesp.br

Key Words: dental porcelain, zirconium, material resistance.

e-mail: adabo@foar.unesp.br r

\begin{abstract}
The aim of this study was to characterize a conventional and a pressed porcelain for zirconia core as to biaxial flexural strength (BFS), apparent fracture toughness (FT) and microstructure composition, and to investigate the effect of glaze cooling rate on the BFS of the zirconia/porcelain bilayers. Monolayers of conventional porcelain Vita VM9 and pressed porcelain Vita PM9 $(n=15)$ (12 mm diameter $x 1.2 \mathrm{~mm}$ thick) were prepared for the BFS test (MPa). Apparent fracture toughness (MPa.m $1 / 2$ ) was measured by indentation technique $(n=15)$. $t$-Student test was performed for statistical analysis. Scanning electron microscopy and $\mathrm{x}$-ray diffraction were used to analyze the porcelain's microstructure. For the BFS of bilayers, zirconia discs (12 mm diameter $x 1 \mathrm{~mm}$ thick) (Vita In-Ceram YZ) were veneered with the two porcelains ( $1 \mathrm{~mm}$ thick). After the glaze firing simulation, the specimens were submitted to fast or slow cooling $(n=15)$. Apparent fracture toughness (MPa.m $1 / 2)$ was measured on the porcelain surface of bilayers $(n=15)$ and residual stress was calculated. Two-way ANOVA (porcelain and cooling method) was used for the bilayer analysis $(\alpha=0.05)$. Vita PM9 monolayer exhibited significantly higher BFS $(p<0.01)$, but there was no significant difference $(p=0.41)$ in the FT between the porcelains. For bilayer specimens, the two-way ANOVA for BFS was significant for the porcelain variable only $(p<0.01)$ better for Vita PM9/zirconia. Two-way ANOVA for the FT for the bilayers was not significant for any variable. All groups showed compressive residual stresses. The pressed porcelain seems to be mechanically more effective for zirconia veneering.
\end{abstract}

, 
hand, some authors found better results with fast cooling $(4,14)$ with regards to flexural strength $(14)$ and porcelain bond strength (4).

The porcelain can be applied by the conventional handlayer technique onto the zirconia or by the press technique, which theoretically is more homogenous (15) and would minimize the effects of internal porosity, improving the mechanical performance (16-18), which may cause less chipping rates. Moreover, press technique is less sensitive and less time dependent, and it allows to try-in the wax pattern before pressing (15). Nevertheless, the behavior of the pressed porcelains for zirconia veneering towards the different cooling methods on the glaze-firing phase is still unclear, since the first cooling of pressed porcelains is necessarily slow, as it occurs in the investment inside and must not be cooled rapidly because of the fracture risk for the ceramic.

Thus, the purpose of this study was to characterize a conventional (Vita VM9) and pressed porcelain (Vita PM9) as to flexural strength, apparent fracture toughness, and microstructure analysis, as well as the effect of the glaze cooling method (last stage) on the biaxial flexural strength and apparent fracture toughness of zirconia/porcelain bilayers. The null hypothesis was that there is no significant difference between the pressed and conventional porcelains in terms of mechanical properties and microstructure, as well as in the mechanical behavior of porcelain/zirconia bilayers when different cooling methods were used (fast or slow).

\section{Material and Methods}

The characteristics of materials used in this study are in Table 1.

\section{Preparation of Porcelain Monolayers}

Monolayer specimens $(12 \mathrm{~mm}$ diameter and $1.2 \mathrm{~mm}$ thick) were prepared from the conventional porcelain (Vita VM9; Vita Zahnfabrik, Bad Säckingen, Baden-Württemberg,
Germany) and the pressed porcelain (Vita PM9; Vita Zahnfabrik) using the conventional and pressed methods respectively $(n=15)$.

To prepare Vita VM9 discs, an oversized polyether mold (Impregum F, 3M ESPE, Seefeld, Baviera, Germany) was used. The porcelain slurry was prepared by mixing the powder and liquid in a ratio of 2.5:1 and inserted in the mold. Excess liquid was blotted with absorbent paper before the specimens were removed from the mold. The VM9 specimens were sintered according to the manufacturer's instructions.

To prepare Vita PM9 specimens, a waxing up was performed in a metallic matrix $(12 \mathrm{~mm}$ diameter and $1.4 \mathrm{~mm}$ thick). The wax patterns were attached to wax sprues and invested according to the manufacturer's recommendations. After wax elimination in the oven (EDG 3P-S 3000; EDG, São Carlos, SP, Brazil) at $850{ }^{\circ} \mathrm{C}$, the ring was transferred to the press oven (Aluminipress; EDG). A Vita PM9 press pellet was placed into the hole left by the sprue before in the investment ring together with a disposable press plunger for pressing the pellets following the manufacturer's heating program. After firing, the set was removed from the furnace at $500{ }^{\circ} \mathrm{C}$ and cooled down to room temperature. After divesting, the samples were cut off from the press sprue using a diamond disc.

The porcelain surfaces of VM9 and PM9 specimens were sequentially ground using 120- to 2000-grit wet $\mathrm{SiC}$ paper discs (Saint-Gobain, Norton Abrasivos, São Paulo, SP, Brazil) in a polishing machine (Metaserv 2000; Buehler UK Ltd, Coventry, UK) until the final dimensions were achieved, measured with a digital caliper (Absolute; Mitutoyo Corporation, Tokyo, Japan).

\section{Biaxial Flexural Strength Test for Monolayers}

Biaxial flexural strength test was carried out according to ISO 6872 (19) for dental ceramic. The test (piston on three balls) was performed in a universal testing machine (DL 2000, EMIC, São José dos Pinhais, PR, Brazil) at a crosshead speed of $1.0 \mathrm{~mm} / \mathrm{min}$ until failure. The specimens were

Table 1. Specifications of the materials used in the current study

\begin{tabular}{|c|c|c|c|c|}
\hline Material & Brand Name & Manufacturer & Chemical composition (8) & Batch number \\
\hline $\begin{array}{l}\text { Y-TZP } \\
\text { ceramic }\end{array}$ & $\begin{array}{l}\text { Vita In-Ceram YZ } \\
(39 \times 9 \times 15.5)\end{array}$ & $\begin{array}{l}\text { Vita Zahnfabrik, Bad } \\
\text { Säckingen, Germany }\end{array}$ & $\begin{array}{c}\text { Zirconia powder: } \mathrm{Al}_{2} \mathrm{O}_{3} \\
(67 \%) \mathrm{ZrO}_{2}(33 \%) \\
\text { Ce-stabilized zirconia glass powder: } \mathrm{Al}_{2} \mathrm{O}_{3}(14-18 \%), \mathrm{SiO}_{2} \\
(14-18 \%), \mathrm{B}_{2} \mathrm{O}_{3}(11-15 \%), \mathrm{TiO}_{2}(2-7 \%), \mathrm{La}_{2} \mathrm{O}_{3}(25-30 \%), \\
\mathrm{CeO}_{2}(6-10 \%), \mathrm{CaO}(4-8 \%), \mathrm{ZrO}_{2}(1-4 \%), \mathrm{Y}_{2} \mathrm{O}_{3}(2-6 \%)\end{array}$ & 35,600 \\
\hline $\begin{array}{l}\text { Feldspathic } \\
\text { ceramic }\end{array}$ & $\begin{array}{l}\text { Vita VM9, 2M2 } \\
\text { base dentine }\end{array}$ & $\begin{array}{l}\text { Vita Zahnfabrik, Bad } \\
\text { Säckingen, Germany }\end{array}$ & $\begin{array}{c}\mathrm{SiO} 2(60-64 \%), \mathrm{Al}_{2} \mathrm{O}_{3} \\
(13-15 \%), \mathrm{K}_{2} \mathrm{O}(7-10 \%), \mathrm{Na}_{2} \mathrm{O}(4-6 \%), \mathrm{TiO}_{2}(<0.5 \%), \mathrm{CeO}_{2} \\
(<0.5 \%), \mathrm{ZrO}_{2}(0-1 \%), \mathrm{CaO}(1-2 \%), \mathrm{B}_{2} \mathrm{O}_{3}(3-5 \%), \mathrm{BaO} \\
(1-3 \%), \mathrm{SnO}_{2}(<0.5 \%), \mathrm{Mg}, \mathrm{Fe} \text { and } \mathrm{P} \text { oxides }(<0.1 \%)\end{array}$ & 12,570 \\
\hline $\begin{array}{l}\text { Feldspathic } \\
\text { ceramic }\end{array}$ & $\begin{array}{l}\text { Vita PM9, } \\
\text { 2M2P-0 opaque }\end{array}$ & $\begin{array}{l}\text { Vita Zahnfabrik, Bad } \\
\text { Säckingen, Germany }\end{array}$ & $\begin{array}{c}\mathrm{SiO}_{2}(62-67 \%), \mathrm{Al}_{2} \mathrm{O}_{3} \\
(16-19 \%), \mathrm{K}_{2} \mathrm{O}(6-8 \%), \mathrm{Na}_{2} \mathrm{O}(5-8 \%), \mathrm{B}_{2} \mathrm{O}_{3}(1-3 \%)\end{array}$ & 17,290 \\
\hline
\end{tabular}


placed concentrically on 3 hardened steel balls with a 2.5 $\mathrm{mm}$ diameter, positioned $120^{\circ}$ apart on a support circle with a $10 \mathrm{~mm}$ diameter. The load was applied with a flat punch with a $1.4 \mathrm{~mm}$ diameter at the center of the specimen. The biaxial flexural strength calculus was performed according to ISO 6872 (19).

\section{Apparent Fracture Toughness Test for Monolayers}

The apparent fracture toughness was measured by the Vickers hardness indentation technique using an indentation tester (Micromet 2100; Buehler UK Ltd) following the ASTM C 1421-99 standard (20). Three indentations $(9.8 \mathrm{~N}, 30 \mathrm{~s})$ were performed in each specimen fractured in a biaxial flexural strength test. To standardize the slow crack growth started by the tension area after loading, the crack length measurement was performed 30 $s$ after the indentation (21).

\section{Microstructural Analyses of Monolayers}

XRD (X-ray diffraction) analyses in the VM9 powder, sintered VM9, PM9 press pellet, and pressed PM9 were performed in a diffractometer (XRD 6000, Shimadzu, Tokyo, Japan) with $\mathrm{Cu} \mathrm{K} \alpha \mathrm{X}$-ray scanning from 10 to $80^{\circ}$ $\vec{s} 2 \theta$ degrees with a step size of $0.05^{\circ}$ and $3 \mathrm{~s} \mathrm{step} \mathrm{interval.}$

For the SEM (Scanning Electron Microscopy) analyses $(n=3)$ of VM9, PM9 and PM9 press pellet specimens, the specimens were polished and etched with $2 \% \mathrm{HF}$ (hydrofluoric acid) for $15 \mathrm{~s}$ and sputter-coated with goldpalladium. The specimens were examined in a scanning electron microscope (JEOL - JSM 6510, Jeol, Tokyo, Japan), operating at $10 \mathrm{kV}$. Three scanning electron micrographs from each group were obtained at a magnification of 500x, $1000 \times$ and $2000 x$. The Image J software (National Institutes of Health, Bethesda, MD, USA) was used to analyze the crystalline phase concentration of VM9, PM9 press pellet and pressed PM9. The SEM images of 1000x magnification $(n=9)$ were used to measure the crystalline area, three times per image. The mean of the measurements was used for statistical analysis.

\section{Preparation of Bilayers}

Sixty pre-sintered zirconia (Vita In-Ceram YZ, Vita Zahnfabrik) were finished using 600-grit size SiC papers in a polishing machine, sintered in the oven (Vita Zyrcomat, Vita Zahnfabrik) at $1530^{\circ} \mathrm{C}$ for $2 \mathrm{~h}$ with $1.5 \mathrm{~h}$ of rising time and cooling until $200{ }^{\circ} \mathrm{C}$, according to the manufacturer's recommendation. After sintering, the discs were $12 \mathrm{~mm}$ diameter and $1 \mathrm{~mm}$ thick.

The zirconia discs to be veneered with VM9 were cleaned by a cleaning firing procedure according to the manufacturer's instructions. The powder and liquid of Vita VM9 were mixed to obtain a thin aqueous mixture (washbake layer), which was applied very thinly with a brush on the cleaned zirconia framework. The firing of the washbake layer was carried out following the manufacturer's recommendations. The discs were placed inside an oversized polyether mold with the washbake layer upward. The porcelain was applied into the mold as previously described, and the sintering was conducted (first dentine firing) and followed by a second dentine firing for correcting the final shape $2.0 \mathrm{~mm}$ thick $(1 \mathrm{~mm}$ of zirconia and $1 \mathrm{~mm}$ of veneer porcelain) and $12 \mathrm{~mm}$ diameter.

To prepare the bilayered zirconia specimens with the pressed Vita PM9 porcelain, the zirconia disc was positioned inside a metallic matrix ( $12 \mathrm{~mm}$ diameter and $2 \mathrm{~mm}$ thick) and was waxed up, obtaining $1 \mathrm{~mm}$ of zirconia layer and $1 \mathrm{~mm}$ of wax layer. The investing, pressing, cooling and divesting procedures were performed as described previously. The bilayered disc was cut out from the press sprue by a diamond disc.

The finishing and polishing procedures were similar to the monolayered groups, until a 2-mm-thick layer $(1 \mathrm{~mm}$ zirconia and $1 \mathrm{~mm}$ veneer porcelain) and $12 \mathrm{~mm}$ diameter were achieved.

\section{Cooling Protocols}

After polishing, the bilayered specimens (VM9 and PM9) were submitted to a self-glaze firing, according to the manufacturer's instructions. The specimens were divided into 2 sub-groups: 1) Fast cooling: immediate removal of the specimens after the end of firing $\left(900^{\circ} \mathrm{C}\right)$, leaving them on the bench until they achieve the room temperature and 2) Slow cooling: after the end of firing, the oven was switched off and kept closed with the specimens inside, until dropping to room temperature.

\section{Biaxial Flexural Strength for Bilayers}

The biaxial flexural strength test of the bilayered specimens followed the same configuration used for the monolayered specimens. The porcelain side was positioned downward under tensile stress (Fig. 1).

The following equation was used to calculate the biaxial flexural strength, according to Lin et al. (22):

$$
\sigma=\frac{6 M}{t_{a}^{2} K_{2 p}}\left[\frac{E_{b} t_{b}\left(1-v_{a}^{2}\right)}{E_{b} t_{b}\left(1-v_{a}^{2}\right)}+\frac{t_{a}\left(1-v_{a}^{2}\right)\left(1+\frac{t_{b}}{t_{a}}\right)\left(1+\frac{E_{a} t_{a}}{E_{b} t_{b}}\right)}{t_{b}\left(\left[1+\frac{E_{a} t_{a}}{E_{b} t_{b}}\right)\right]^{2}-\left(\left[v_{2} \frac{v_{b} E_{2} t_{2}}{E_{b} t_{b}}\right)\right]^{2}}\right]
$$

Where $\sigma$ is the biaxial flexural strength, $M$ is the maximum bending moment, and $t_{a}$ and $t_{b}$ are the thicknesses of zirconia and porcelain layers, respectively. $E_{a}$ e $E_{b}$ are the Young's modulus of zirconia (210 GPa) and porcelain $(65 \mathrm{GPa})$, respectively. The Poisson's ratio of zirconia $\left(v_{\mathrm{a}}\right)$ and porcelain $\left(v_{b}\right)$ was 0.25 . The $K_{2 p}$ was obtained by the 
following equation:

$$
K_{2 p}=1+\frac{E_{b} t_{b}^{3}\left(1-v_{a}^{2}\right)}{E_{a} t_{a}^{3}\left(1-v_{b}^{2}\right)}+\frac{3\left(1-v_{a}^{2}\right)\left(1+\frac{t_{b}}{t_{a}}\right)^{2}\left(1+\frac{E_{a} t_{a}}{E_{b} t_{b}}\right)}{\left(1+\frac{E_{a} t_{a}}{E_{b} t_{b}}\right)^{2}-\left(\left[v_{2}+\frac{v_{b} E_{a} t_{a}}{E_{b} t_{b}}\right)\right]^{2}}
$$

$M$ value was obtained by:

$$
M=\frac{W}{4 \pi}\left[\frac{(1+v) \log A}{R}+1\right]
$$

Where $W$ is the load, $v$ is the Poisson's ratio of bilayer, $A$ is the radius of the circle of support points, and $R$ is the equivalent radius of loading calculated by:

$$
R=\sqrt{1,6 B^{2}+d^{2}}-0,675 d
$$

Where $B$ is the radius of the tip of the piston and $d$ is the thickness of specimens.

\section{Mode of Failure Analysis}

After the test, the type of fracture was observed by visual analysis, classified as only porcelain fracture or complete fracture (zirconia and porcelain fracture). The zirconia/porcelain interface was analyzed by SEM in three fractured specimens randomly selected from each group. Qualitative fractographic analysis was performed.

\section{Apparent Fracture Toughness Test for Bilayers}

The porcelain apparent fracture toughness in bilayer specimens was measured by indentation technique, as described for the monolayers' test $(n=15)$.

\section{Residual Stress Measurements}

To calculate the residual stress on the porcelain surface of the bilayer specimens after slow and fast cooling requires measuring fracture toughness before and after the ultimate firing (glaze). Ten specimens of VM9/zirconia and 10 specimens of PM9/zirconia were made according to previous description. After polishing, the apparent fracture toughness was measured by the Vickers hardness indentation technique (21), as described before. For each specimen, three indentations $(9,8 \mathrm{~N} ; 30 \mathrm{~s})$ were performed to calculate the fracture toughness $(n=5)$. The bilayer specimens were submitted to a self-glaze firing, according to the manufacturer's instructions, cooled by slow or fast cooling method and final fracture toughness was measured after glazing $(n=5)$. Residual stress (MPa) was calculated according to the following equation (23):

$$
\sigma_{r}=\frac{K_{I C}-K_{I C \prime}}{2 \sqrt{\frac{c}{\pi}}} \times 1000
$$

Where, $\mathrm{K}_{\mathrm{lc}}$ is the fracture toughness measured before glaze cooling, $\mathrm{K}_{\mathrm{Ic}}$ is the fracture toughness measured after glaze cooling (slow or fast), and $\mathrm{c}$ is the half size of the median crack measured before the glaze cooling.

\section{Statistical Analysis}

The statistical analysis for monolayers (biaxial flexural strength and apparent fracture toughness) was performed by Student-t test. One-way ANOVA was used for analyzing the crystalline phase concentration. Two-way ANOVA (porcelain and cooling method) followed by Tukey's Honestly Significant Difference (HSD) post hoc test were used to analyze the biaxial flexural strength and apparent fracture toughness of the bilayered specimens $(\alpha=0.05)$. The used software was SPSS 19.0 (Statistical Package for Statistical Science Inc, Chicago, IL, USA).

\section{Results}

The Student's t tests performed for monolayer specimens revealed that the biaxial flexural strength of the pressed
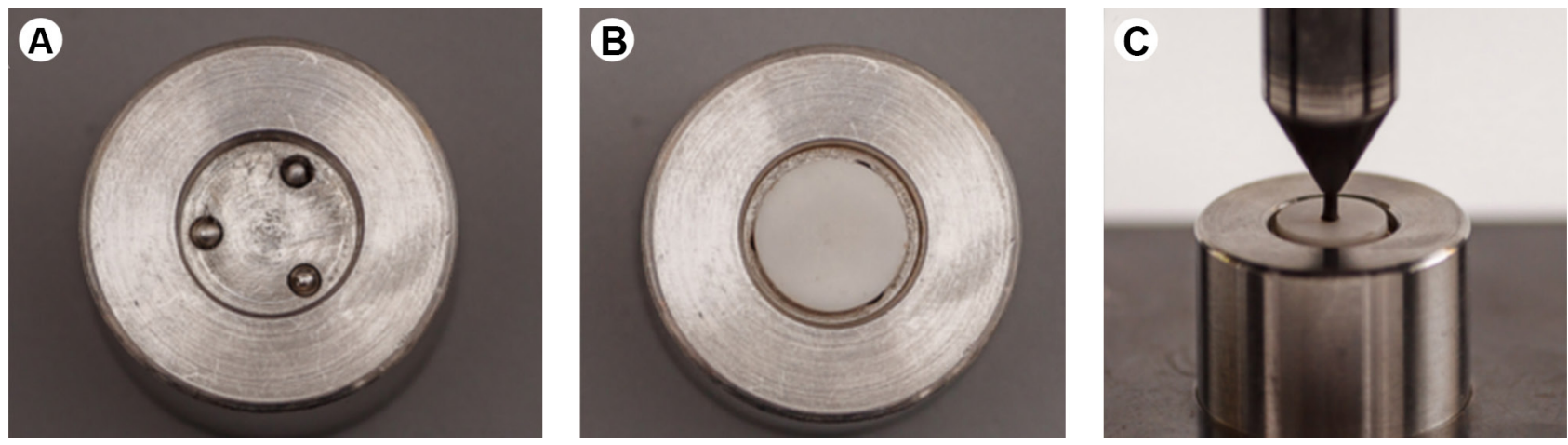

Figure 1. A: Device with three balls to support the discs. BH Bilayer specimen positioned with the porcelain in contact with three balls (in tension). C: Photograph of the biaxial flexural strength test showing zirconia in contact with the piston. 
feldspathic porcelain Vita PM9 exhibited significantly higher values $(105.20 \pm 10.91 \mathrm{MPa})$ than the conventional VitaVM9 $(81.76 \pm 7.72 \mathrm{MPa})(\mathrm{p}<0.01)$. Regarding fracture toughness, no significant difference $(p=0.41)$ was observed between Vita VM9 $\left(1.59 \pm 0.1 \mathrm{MPa}^{\mathrm{m}} \mathrm{m}^{1 / 2}\right)$ and Vita PM9 $\left(1.62 \pm 0.08 \mathrm{MPa} . \mathrm{m}^{1 / 2}\right)$.

The XRD showed that both porcelains have leucite in composition as a crystalline phase before or after sintering (VM9) or pressing (PM9). SEM analysis showed a similar microstructure for VM9 (Fig. 2), pressed PM9 (Fig. 3) or pressed pellet (Fig. 4). The crystalline phase concentration was: PM9 pellet $=19.5 \pm 3.2 \%$; PM9 pressed $=18.4 \pm 2.1 \%$; $\mathrm{VM} 9=21.5 \pm 2.7 \%$, and one-way ANOVA was not significant $\left(F_{2,24}=2.9541, p=0.07\right)$.

The means of the flexural strength $(\sigma, \mathrm{MPa})$ and standard deviations (SD) of the bilayers biaxial flexural strength, cooled at slow or fast rate were: VM9/Slow = $167.15 \pm 30.53$; VM9/Fast $=186.83 \pm 51.45 ; \mathrm{PM9} /$ Slow $=$

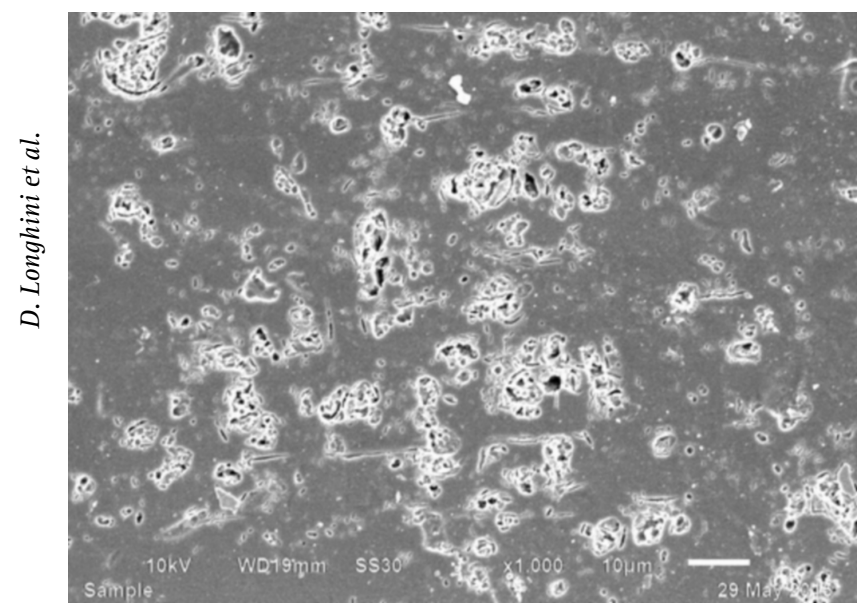

Figure 2. SEM images at 1000× magnification of Vita VM9.

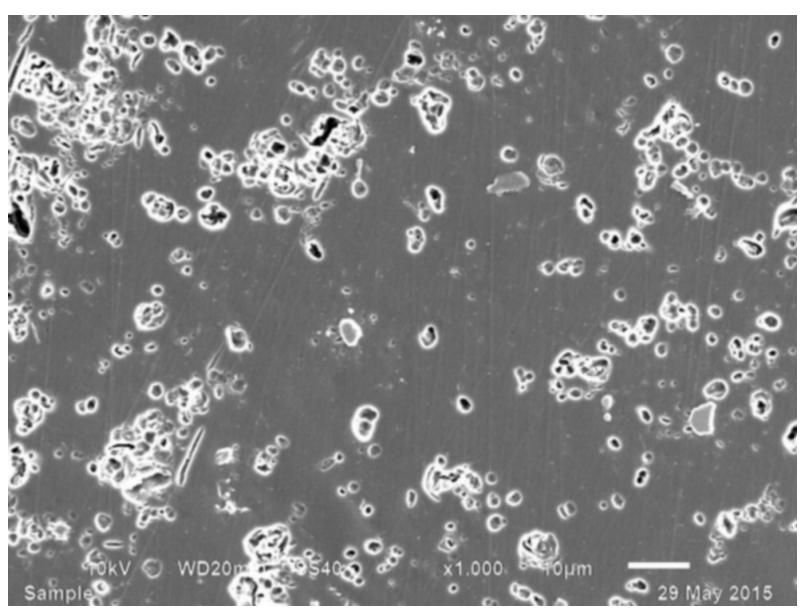

Figure 3. SEM images at 1000x magnification of Vita PM9 pressed.
$234.89 \pm 49.19 ;$ PM9/Fast $=232.24 \pm 40.55$. The two-way ANOVA was performed for the biaxial flexural strength (MPa) of the bilayered specimens for the porcelain material and the cooling method variables. This analysis indicated significance only for the porcelain material variable $(p<0.01)$ better for the bilayer Vita PM9/zirconia.

With regards to fracture characteristics, 4 specimens showed complete fractures (13.3\%) and 26 showed only porcelain fractures $(86.6 \%)$ in VM9/zirconia group, but for the PM9/zirconia group, 10 discs failed in complete fractures (33.3\%) and 20 showed only porcelain fractures (66.6\%). A fractographic analysis of VM9 bilayer and PM9 bilayer showed that the fracture originated from defects in the porcelain layer. Cracks started from the porcelain surface and from the zirconia/porcelain interface, which may propagate each other to extend through the specimen (Figs. 5 and 6).

There was no statistically significant difference among the groups in apparent fracture toughness of porcelain in the bilayers (Slow $/ \mathrm{VM} 9=0.99 \mathrm{MPa} \cdot \mathrm{m}^{1 / 2}$, Fast $/ \mathrm{VM} 9=1.06$ MPa. $\mathrm{m}^{1 / 2}$, Slow $/ \mathrm{PM9}=1.10 \mathrm{MPa} \cdot \mathrm{m}^{1 / 2}$ and Fast $/ \mathrm{PM} 9=1.12$ MPa. $\mathrm{m}^{1 / 2}$ ). All the specimens showed compressive residual stress (MPa): Slow/VM9 $=-5.19 \mathrm{MPa}$; Fast/VM9 $=-16.5$ MPa; Slow/PM9 = -11.62 MPa; Fast/PM9 = -13.03 MPa.

\section{Discussion}

Besides the similarity in composition between the studied porcelains, as revealed in the XRD analysis and crystalline phase concentration, the higher values of biaxial flexural strength for the monolayer pressed porcelain PM9 compared to the conventional layered VM9 porcelain may be due to the processing technique. In this study, both conventional and pressed porcelain were similar in composition and microstructure. The XRD analysis detected leucite contents, and the SEM images revealed comparable

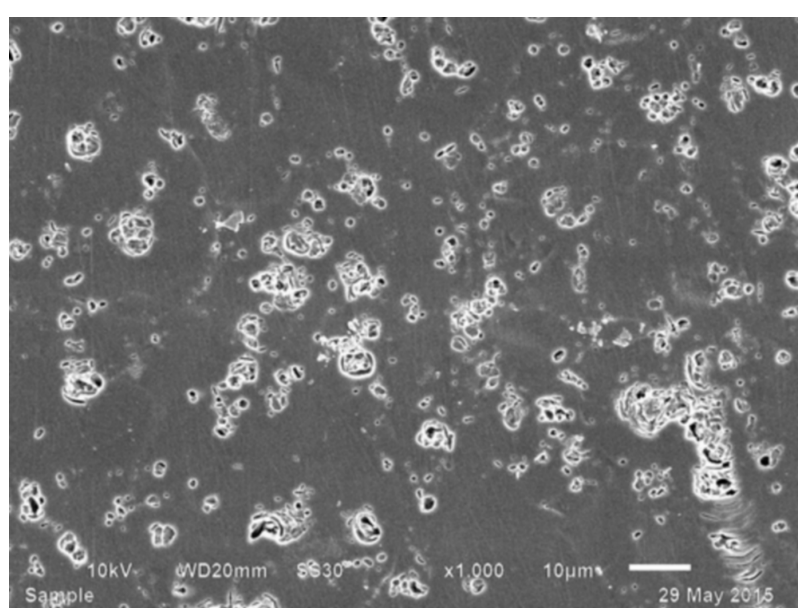

Figure 4. SEM images at 1000× magnification of Vita PM9 press pellet. 
microstructures (Figs. 2-4) and crystal concentration. An explanation may be that there is a possible leucite crystal growth in the PM9 after the pressing cycle, but it was not confirmed since the crystal concentration before and after firing was not different.

The better flexural strength of the pressed porcelains as PM9 may be related to highly controlled manufacturing of the ingots. The prefabricated ingots are melted and overpressed into a previously invested mold cavity in a controlled procedure $(7,16)$, which can achieve a more homogeneous structure, avoiding large pore formation (15). Conversely, in hand-layer technique, the powder and liquid are hand mixed and modeled with a brush, which makes it more susceptible to internal porosity concentration. In addition, it is easy to accumulate other technical errors due to the multiple stages of uncontrolled factors (8). Heintze and Rousson (18) found less frequent veneer chipping rates in pressed technique compared to the conventional one, either for zirconia or metal-ceramic fixed dental prostheses. However, better results were also found for conventional porcelain in some studies $(7,15)$, both attributing it to the lack of dental laboratory experience with the press technique. On the other hand, Lima et al. (8) did not show difference between the VM9 and PM9 porcelains in fourpoint flexural strength after fatigue.

The PM9 porcelain showed a higher performance in the bilayer specimens test. Again, this may be related to the more controlled technique. Moreover, some studies showed that pressed porcelains have better wetting with the zirconia substructure, due to the pressure and vacuum during injection $(16,22)$. Kim et al. (17), in failure analysis, observed that in the conventional porcelain group, the fracture was always found in the porcelain body, while the pressed porcelain group showed mainly the complete

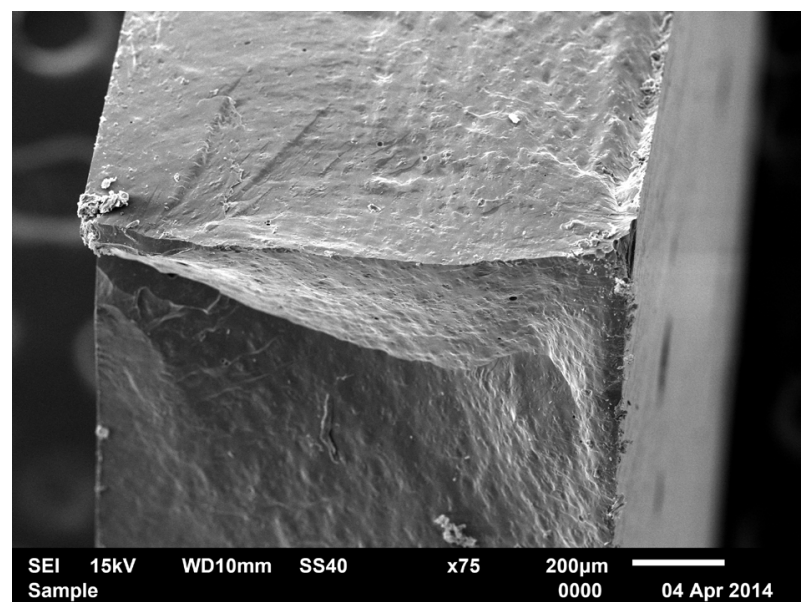

Figure 5. SEM images at $75 \times$ magnification showing fracture of VM9 bilayer starting from internal defect close to the interface propagating to the surface. fracture of the zirconia/porcelain set. They attributed the low resistance of the conventional porcelain to technical failures and structural weakness caused by internal porosities and the higher resistance of pressed porcelain to its stronger adhesion to zirconia (17). In the present study, there was more incidence of zirconia/porcelain combined fracture in the group with PM9 compared to the VM9 group. The fractographic qualitative analysis shows that for both PM9 and VM9 bilayer specimens, the fracture started from internal defect close to the interface and from the surface. The study of Guazzato et al. (24) explained that different fracture modes could occur depending on the setting of biaxial flexural strength testing. It is influenced by the material at the bottom and physical properties such as elastic modulus of the bilayer specimen materials. When the porcelain is on the bottom, as it was in the present study, the fracture likely starts from a major defect at the surface to propagate to the inside (24). In the conducted study, defects at the interface may originate a secondary crack initiation.

With regard to the cooling rate in the firing cycle, an increasing number of authors propose slow cooling $(2,10,13)$, aiming to reduce the thermal gradient by a homogeneous cooling of internal and external porcelain surface below $T_{g}(13)$. This would avoid excessive development of high magnitude transient stresses (13). However, some studies observed better results for fast cooling $(4,14)$. Almeida-Junior et al. (14) suggested that compressive stress is developed at the fast cooled veneering porcelain, which could improve the resistance of the surface layer but may develop high tension stress at the zirconia/ porcelain interface (14). However, better results of bond strength were observed by Göstemeyer et al. (4) associated with compressive stress in the veneering porcelain, which

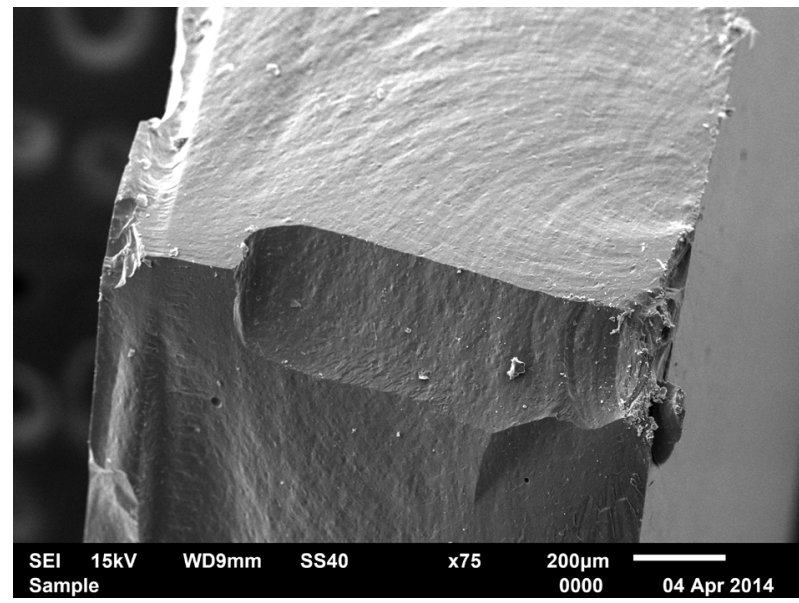

Figure 6. SEM images at $75 \times$ magnification of broken PM9 bilayer showing fracture originating at interface from defects in the porcelain layer. 
would protect the adhesion interface (4). In this study, all groups showed compressive residual stress on surface after both slow and fast glaze cooling. This may be explained by the thermal gradients generated after cooling, since the Y-TZP conducts substantially less heat than veneer porcelain (10). Due to the tempering effect, the residual stresses distribution change from the surface to the bulk, with compressive stresses at the surface and compensating tensile stress in the bulk $(3,11)$. Residual stress may be related to cooling rate, material thickness, and thermal properties such as thermal expansion coefficient, conductivity and diffusivity (11). Higher values of compressive residual stress were found in fast cooling methods, particularly for VM9. This result may be related to differences between pressed technique (PM9) and conventional technique (VM9) or because the higher mismatch of the thermal coefficient expansion between zirconia infrastructure $\left(10.5 \mathrm{ppm} /{ }^{\circ} \mathrm{K}\right)$ and VM9 (8.8-9.2 ppm/ ${ }^{\circ}$ K), rather than that for PM9 (9$\left.9.5 \mathrm{ppm} /{ }^{\circ} \mathrm{K}\right)$.

It is important to highlight that in the clinical routine the crowns are finished before glazing, different from several studies, where the specimens are usually finished after the cooling method $(4,14)$. Taking into account that $\vec{\approx}$ compressive stresses in a zirconia/porcelain bilayer after the sintering are locked on the surface of veneer, the compression zone on the surface may be relieved when finishing is performed (25). In the present study, specimens were polished prior the final glaze firing. Nevertheless, no significant difference was found for the fast and slow cooling rates.

Fracture toughness is related to the mechanical resistance of the material to the catastrophic failure, defined as the critical stress intensity level at which a given flaw starts growing (21). In contrast to the flexural strength results, the statistical results for apparent fracture toughness were not significant either for monolayer or bilayer specimens. However, for monolayer specimens the values were higher (1.59 to $1.62 \mathrm{MPa} . \mathrm{m}^{1 / 2}$ ) than those for the bilayers ( 0.99 to $1.12 \mathrm{MPa} \cdot \mathrm{m}^{1 / 2}$ ). Although this is not the main objective of the study, the lower fracture toughness of porcelain in bilayer specimens may be associated to residual stresses and may make the porcelain weaker and more susceptible to chipping. According to Pang et al., more chipping rates in zirconia/porcelain restorations may be associated to greater residual stresses and low fracture toughness of the veneering porcelain (6). With regard to the cooling rate for the bilayers, again, it was not able to interfere in the fracture toughness.

As a limitation, it may be reminded that the study was performed in flat specimens (discs), which can be difficult for the clinical conditions. Moreover, the mechanical properties were evaluated by means of static testing.
Further studies about all-ceramic zirconia/porcelain crowns or bridges under fatigue could help in understanding the intraoral behavior of these systems.

In conclusion, pressed porcelain may have better mechanical behavior because it has higher flexural strength than the conventional hand layered porcelain, either in monolayer or bilayer structures, despite the similarity in apparent fracture toughness, composition and microstructure. The cooling rates did not impair the biaxial flexural strength and apparent fracture toughness in bilayer specimens, but fast cooling increased compressive residual stress on porcelain surface, particularly for the conventional VM9.

\section{Resumo}

Este estudo teve como objetivo caracterizar uma porcelana convencional e uma prensada indicadas para infraestrutura de zircônia em termos de resistência à flexão biaxial (RFB), tenacidade à fratura aparente (TF) e composição microestrutural, e investigar o efeito da taxa de resfriamento do ciclo de glaze na RFB de espécimes bicamada de zircônia/porcelana. Espécimes monocamada de porcelana convencional Vita VM9 e porcelana prensada Vita PM9 $(n=15)$ (12 mm de diâmetro x 1,2 mm de espessura) foram preparados para o ensaio de RFB (MPa). Tenacidade à fratura aparente (MPa.m ${ }^{1 / 2}$ ) foi mensurada pela técnica da indentação $(n=15) .0$ teste de t-Student foi aplicado para as análises estatisticas. Microscopia eletrônica de varredura e difração de raios- $X$ foram utilizadas para análise microestrutural da porcelana. Para o ensaio de RFB nos bicamadas, discos de zircônia (12 mm de diâmetro $\times 1 \mathrm{~mm}$ de espessura) (Vita In-Ceram YZ) foram recobertos com as duas porcelanas (1 $\mathrm{mm}$ de espessura). Após a simulação da queima de glaze, os espécimes foram submetidos ao método de resfriamento rápido ou lento $(n=15)$. A tenacidade à fratura aparente (MPa.m $1 / 2$ ) foi mensurado na superficie da porcelana dos bicamadas $(n=15)$ e o estresse residual foi calculado. Foi utilizado ANOVA a dois fatores (porcelana e método de resfriamento) para análise estatística dos espécimes bicamada $(\alpha=0,05)$. Monocamadas de Vita PM9 exibiram valores de resistência à flexão biaxial significativamente maiores $(p<0,01)$, mas não houve diferença estatística $(p=0,41)$ em relação à TF entre as porcelanas. Para os espécimes bicamada, ANOVA a dois fatores para RFB foi significante apenas para a variável porcelana $(p<0,01)$, com superioridade para Vita PM9/zircônia. ANOVA a dois fatores para TF dos espécimes bicamadas não apresentou significância para nenhuma variável. Todos os grupos apresentaram estresse residual de compressão. Porcelanas prensadas parecem ser mecanicamente mais efetivas para recobrimento de zircônia.

\section{References}

1. Sailer I, Feher A, Filser F, Gauckler $\sqcup$, Luthy $\mathrm{H}$, Hammerle $\mathrm{CH}$. Five year clinical results of zirconia frameworks for posterior fixed partial dentures. Int J Prosthodont 2007;20:383-388.

2. Choi JE, Waddell JN, Swain MV. Pressed ceramics onto zirconia. Part 2: indentation fracture and influence of cooling rate on residual stresses. Dent Mater 2011;27:1111-1118.

3. Swain MV. Unstable cracking (chipping) of veneering porcelain on all-ceramic dental crowns and fixed partial dentures. Acta Biomater 2009;5:1668-1677.

4. Göstemeyer G, Jendras M, Dittmer MP, Bach F, Stiesch M, Kohorst P. Influence of cooling rate on zirconia/veneer interfacial adhesion. Acta Biomater 2010;6:4532-4538.

5. Pjetursson BE, Sailer I, Makarov NA, Zwahlen M, Thoma DS. All-ceramic or metal-ceramic tooth-supported fixed dental prostheses (FDPs)? A systematic review of the survival and complication rates. Part II: Multiple-unit FDPs. Dent Mater 2015;31;624-639.

6. Pang Z, Chughtai A, Sailer I, Zhang Y. A fractographic study of clinically 
retrieved zirconia-ceramic and metal-ceramic fixed dental prostheses. Dent Mater 2015;31:1198-1206.

7. Guess PC, Bonfante EA, Silva NR, Coelho PG, Thompson VP. Effect of core design and veneering technique on damage and reliability of Y-TZP-supported crowns. Dent Mater 2013;29:307-316.

8. Lima JM, Souza AC, Anami LC, Bottino MA, Melo RM, Souza RO. Effects of thickness, processing technique, and cooling rate protocol on the flexural strength of a bilayer ceramic system. Dent Mater 2013;29:1063-1072.

9. Sailer I, Makarov NA, Thoma DS, Zwahlen M, Pjetursson BE. All-ceramic or metal-ceramic tooth-supported fixed dental prostheses (FDPs)? A systematic review of the survival and complication rates. Part I: Single crowns (SCs). Dent Mater 2015;31:603-623.

10. Tan JP, Sederstrom D, Polansky JR, McLaren EA, White SN. The use of slow heating and slow cooling regimens to strengthen porcelain fused to zirconia. J Prosthet Dent 2012;107:163-169.

11. Mainjot AK, Schajer GS, Vanheusden AJ, Sadoun MJ. Influence of zirconia framework thickness on residual stress profile in veneering ceramic: measurement by hole-drilling. Dent Mater 2012;28:378-384.

12. DeHoff $P H$, Barrett $A A$, Lee $R B$, Anusavice KJ. Thermal compatibility of dental ceramic systems using cylindrical and spherical geometries. Dent Mater 2008;24:744-752.

13. Benetti P, Kelly JR, Della Bona A. Analysis of thermal distributions in veneered zirconia and metal restorations during firing. Dent Mater 2013;29:1166-1172.

14. Almeida AA Jr, Longhini D, Domingues NB, Santos C, Adabo GL. Effects of extreme cooling methods on mechanical properties and shear bond strength of bilayered porcelain/3Y-TZP specimens. J Dent 2013;41:356362.

15. Nadja N, Andreas B, Caroline S, Christoph H, Irena S. A randomized controlled clinical trial of 3-unit posterior zirconia-ceramic fixed dental prostheses (FDP) with layered or pressed veneerin ceramics: 3-year results. J Dent 2015;43:1365-1370.
16. Aboushelib MN, Kleverlaan CJ, Feilzer AJ. Microtensile bond strength of different components of core veneered all-ceramic restorations. Part II: Zirconia veneering ceramics. Dent Mater 2006;22:857-863.

17. Kim JH, Lee SJ, Park JS, Ryu JJ. Fracture load of monolithic CAD/CAM lithium disilicate ceramic crowns and veneered zirconia crowns as a posterior implant restoration. Implant Dent 2013;22:66-70.

18. Heintze SD, Rousson V. Survival of zirconia- and metal-supported fixed dental prostheses: a systematic review. Int J Prosthodont 2010;23:493502.

19. International Organization for Standardization. ISO 6872. Dentistry ceramic materials. Geneva: ISO; 2008.

20. ASTM Standard C1421-99. Standard test method for determination of fracture toughness of advanced ceramics at ambient temperature. West Conshocken, PA:ASTM;1999.

21. Scherrer SS, Denry IL, Wiskott HW. Comparison of three fracture toughness testing techniques using a dental glass and a dental ceramic. Dent Mater 1998;14:246-255.

22. Lin WS, Ercoli C, Feng C, Morton D. The effect of core material, veneering porcelain, and fabrication technique on the biaxial flexural strength and Weibull analysis of selected dental ceramics. J Prosthodont 2012;21:353-362.

23. Cesar PF, Gonzaga CC, Miranda WG, Yoshimura HN. Effect of ion exchange on hardness and fracture toughness of dental porcelains. J Biomed Mater Res B Appl Biomater 2007;83:538-545.

24. Guazzato M, Proos K, Sara G, Swain MV. Strength, reliability, and mode of fracture of bilayered porcelain/core ceramics. Int J Prosthodont 2004;17:142-149.

25. Guazzato M, Quach L, Albakry M, Swain MV. Influence of surface and heat treatments on the flexural strength of Y-TZP dental ceramic. J Dent 2005;33:9-18.

Received March 11, 2016

Accepted May 24, 2016 